\title{
Project ECHO in Belarus: outcomes of 3-year experience
}

\author{
Olga P Matylevich (D) , Minsk, Belarus; Alexander B Shushkevich, Minsk, Belarus; Pavel A Perevoschikov, Minsk, \\ Belarus; Siarhei A Mavrichev, Minsk, Belarus and Kathleen M Schmeler (D) , Houston, USA
}

Belarus is a country in Central Europe with a population of 9.5 million, which borders with Russia, Ukraine, Poland, Lithuania, and Latvia. ${ }^{1}$ The mean age of the population is 39.6 years, almost $80 \%$ are living in urban areas, and the life expectancy for women is 78.9 years and for men is 66.5 years. ${ }^{2}$ Based on the current Human Development Index $(\mathrm{HDI})$, which combines measures of health (life expectancy at birth), education (years of schooling for adults), and standard of living (gross national income per capita), Belarus falls into the second tier of countries with high $\mathrm{HDI}$, compared with other Eastern European countries with very high (first tier) and high HDI. $^{12}$

The Belarusian health system aims to provide universal access to care, which is free at the point of use. ${ }^{3}$ Cancer treatment in Belarus is carried out by nine well-equipped and fully staffed centers. N.N. Alexandrov National Cancer Center of Belarus is a leading clinical and research

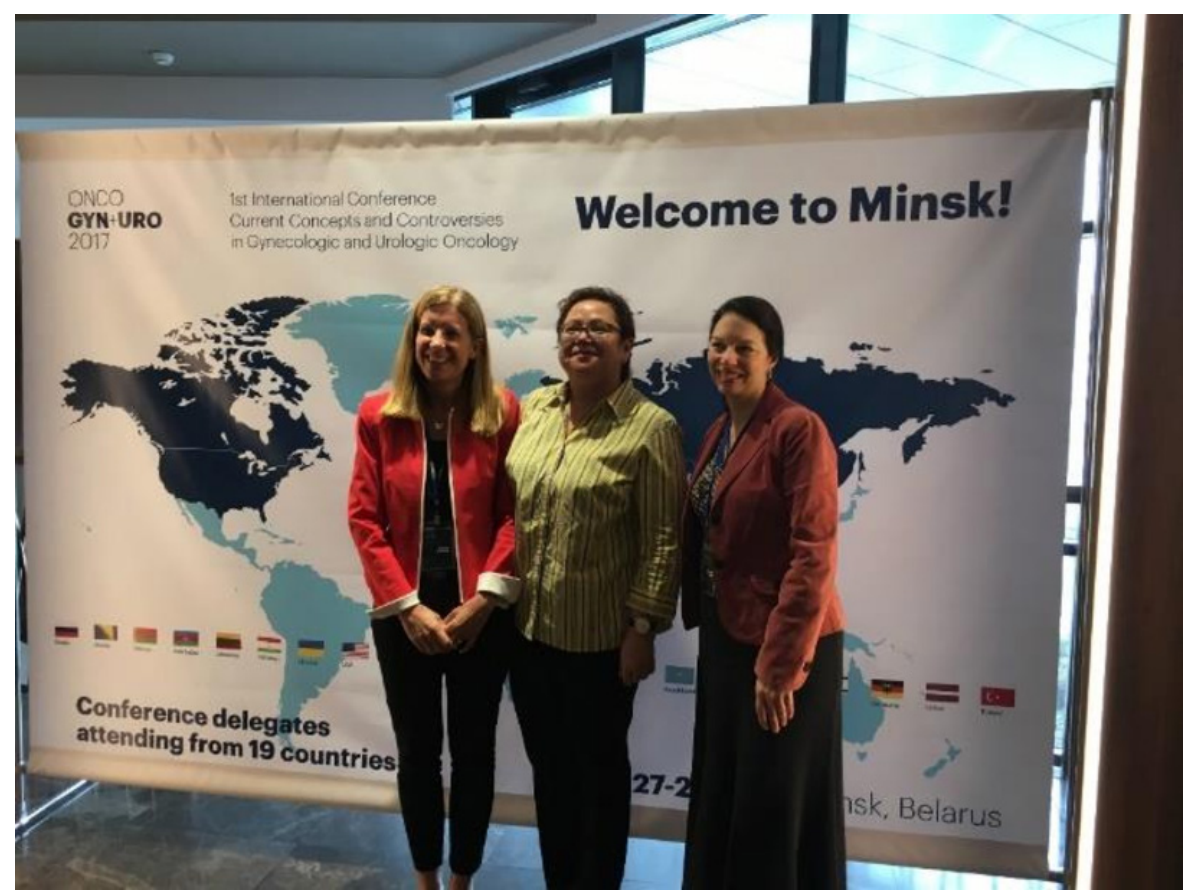

Figure 1 Drs Kathleen Schmeler, Olga Matylevich and Jubilee Brown (from left to right) during the international conference 'Current concepts and controversies in gynecologic and urologic oncology', Minsk, Belarus, 2017. center, which also maintains the Belarusian Cancer Registry. ${ }^{4}$ In 2018, it was estimated that there were 303119 individuals living with cancer in Belarus. Following the 1986 Chernobyl disaster, the number of people diagnosed with cancer annually increased from 26000 in 1990 to 42287 in $2018 .^{5}$

The age-standardized incidence and mortality rates for gynecological cancers in Belarus per 100000 of the female population are: corpus uteri -24.9 and 3.6; ovary - 15.4 and 4.6; cervix - 13.3 and 3.8, respectively. ${ }^{5}$ Belarus had the highest rate of endometrial cancer in the world in 2018 and ranked third in the incidence of ovarian cancer among the top 25 countries with the highest rates of these cancers. ${ }^{6}$

The prevalence of high-risk human papillomavirus (HPV) infection among the general population of women in Belarus is $7.1 \%$. Furthermore, the HPV prevalence among women age 15-63 years with normal cervical cytology in Belarus is approximately

$25 \%$, with $65.4 \%$ of invasive cervical cancers attributable to HPV 16 or $18 .^{7}$ About 979 new cervical cancer cases are diagnosed annually in Belarus, with an age-standardized incidence rate of 13.3 , compared with 16.0 in Eastern Europe with only Poland and Czech Republic being lower. ${ }^{8}$ About 318 cervical cancer deaths occur annually in Belarus, with an age-standardized mortality rate of 3.8 compared with 6.1 in Eastern Europe. It is known that most cervical cancers and related deaths can be avoided by integrated vaccination and HPV-based screening. As of today, there is no national HPV immunization program in Belarus. A nationwide screening program is under development with about $75 \%$ of women being tested opportunistically during annual exams.

In April 2017, Belarus held an international conference 'Current Concepts and Controversies in Gynecologic and Urologic Oncology' organized together with the International Gynecologic Cancer Society (IGCS) and the United States National Cancer Institute. ${ }^{9}$ Leaders in the field of gynecologic oncology from the USA and Belarus met and began international cooperation (Figure 1). Within the framework of this cooperation, Dr Olga Matylevich from the Gynecologic Oncology Department at N.N. Alexandrov National Cancer Center of Belarus visited the Department of Gynecologic Oncology at the University of Texas MD Anderson Cancer Center in Houston, Texas, USA, where she spent 1 month under the guidance of international mentor Dr Kathleen Schmeler (Figure 2). In 2019, Dr Alexander Shushkevich was awarded the IGCS Visiting Scholar fellowship, and spent 2 months in the Gynecologic Oncology Department at the Levine Cancer Institute, Carolinas HealthCare System in Charlotte, North Carolina, USA under the guidance of Dr Jubilee Brown and Dr Wendel Naumann (Figure 3).These observerships gave doctors from Belarus an opportunity to enhance professional skills in clinical care and clinical research, and provided them with mentorship on how to better implement prevention, screening, and treatment 


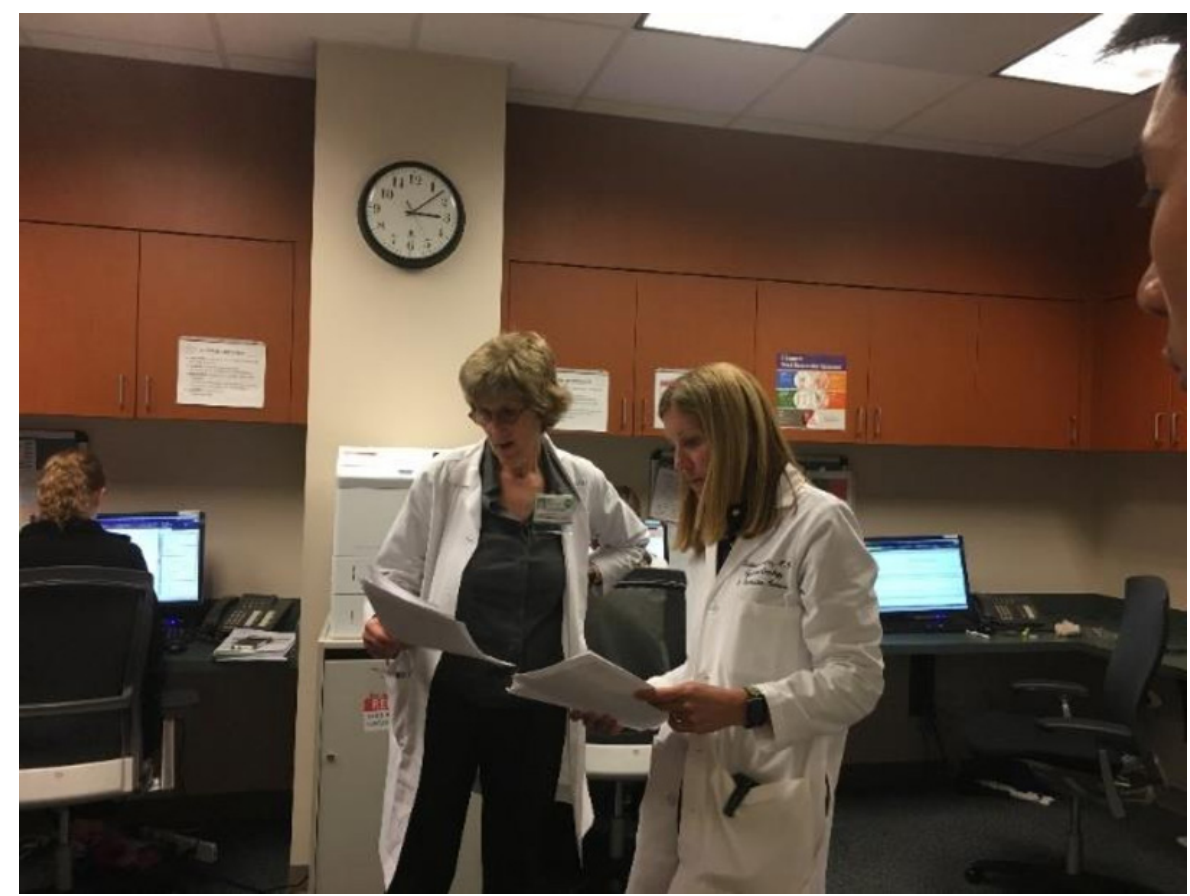

Figure 2 Dr Kathleen Schmeler at the outpatient department of the University of Texas MD Anderson Cancer Center in Houston, USA, 2017.

programs for gynecological cancers in Belarus.

Supported by the IGCS, Belarus began utilizing the Project ECHO (Extension for Community Healthcare Outcomes) model to conduct global virtual tumor boards. It helps Belorussian participants to build expertise and competence in the diagnosis and treatment of gynecologic cancers via case-based analysis of patients by using videoconferencing technology to connect local care providers with world leading experts in gynecologic oncology. The multidisciplinary team of IGCS participants for the Belarus ECHO

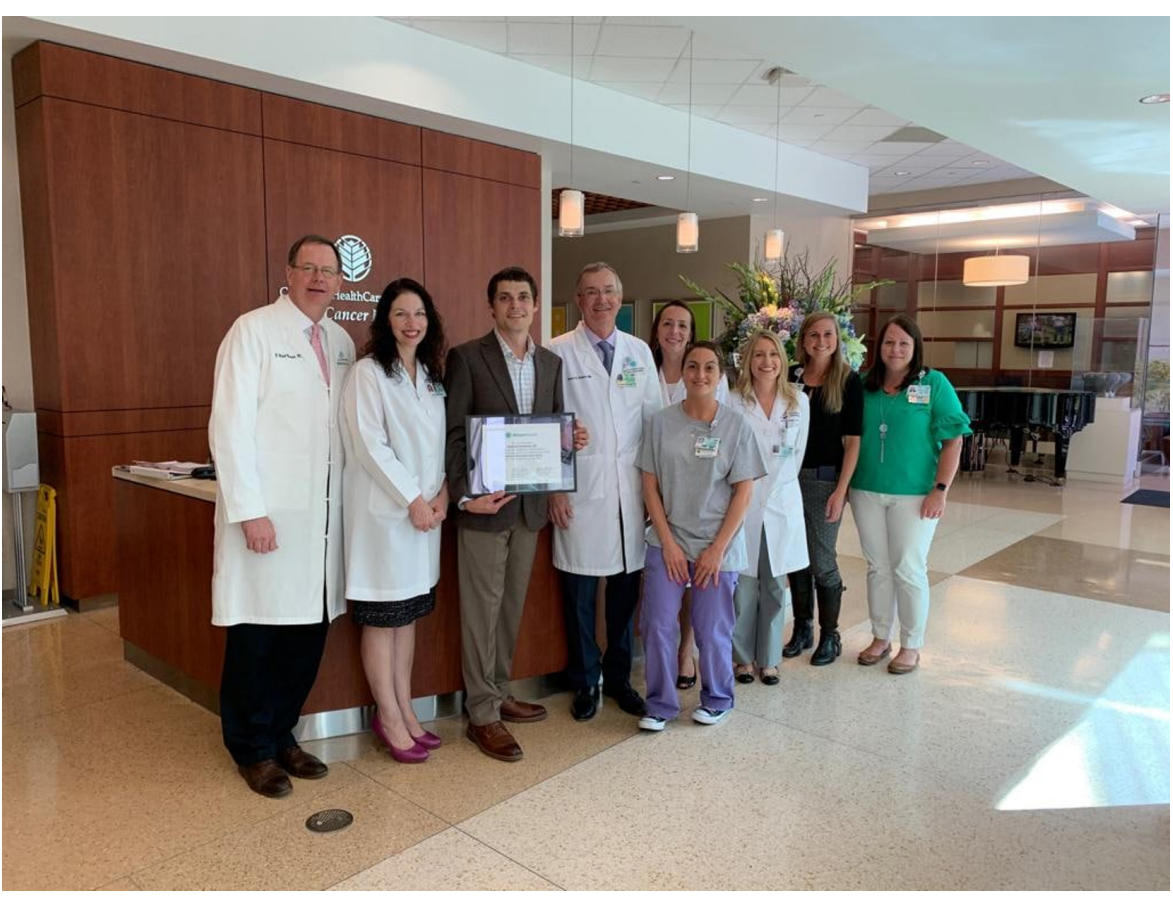

Figure 3 Drs Wendel Naumann, Jubilee Brown and Alexander Shuchkevich (from left to right) with colleagues from the Levine Cancer Institute, Carolinas HealthCare System in Charlotte, North Carolina, USA, 2019. tumor boards includes gynecologic oncologists, pathologists, and radiation oncologists from various regions. Each Project ECHO session is 1 hour in length with $30-45$ min of case presentations and discussion followed by a 15-30 min didactic lecture. To date, 27 ECHO virtual tumor boards have been held between 2017 and 2020. The Belorussian clinical team has presented over 50 difficult patient cases of women with cervical, endometrial, or ovarian cancer including rare histologies. International faculty consultants provided their expert opinions on each case. Future developments of this ECHO project include the introduction follow-up discussions of cases under review. Primary mentors for the program include: Dr Kathleen Schmeler from MD Anderson Cancer Center, Houston, USA; Dr Anna Plotkin from the University of Toronto, Canada; and Dr Ofer Gemer from Barzilai University Medical Center, Ashkelon, Israel.

The Project ECHO tumor boards in Belarus along with faculty exchanges have proven to be useful to support international clinical consulting opportunities that allowed gynecologic oncologists in Belarus to receive the best practice guidance from world leading specialists, and provide up to date care for women in Belarus with gynecologic malignancies.

\section{Correspondence to Dr Olga P Matylevich,} Gynecologic Oncology Department, NN Alexandrov National Cancer Centre, Minsk, Belarus; omatylevich@tut.by

Acknowledgements Mary Eiken, Susan Ralph, Andrei Pletnev, Vitali Petukhov, and all our Belarus Project ECHO collaborators.

Contributors All authors included in this manuscript have contributed to the work being shared for publication.

Funding The authors have not declared a specific grant for this research from any funding agency in the public, commercial or not-for-profit sectors.

Competing interests None declared.

Patient consent for publication Not required.

(c) IGCS and ESGO 2021. No commercial re-use. See rights and permissions. Published by BMJ.

D Check for updates

To cite Matylevich $\mathrm{OP}$, Shushkevich $\mathrm{AB}$, Perevoschikov PA, et al. Int J Gynecol Cancer 2021;31:929-931.

Accepted 1 December 2020

Published Online First 22 December 2020

Int J Gynecol Cancer 2021;31:929-931.

doi:10.1136/ijgc-2020-002284 
ORCID iDs

Olga P Matylevich http://orcid.org/0000-0003-07322101

Kathleen M Schmeler http://orcid.org/0000-00029670-4189

\section{REFERENCES}

1 Learn how the World Bank group is helping countries with COVID-19 (coronavirus). Available: https://data.worldbank.org/ country/BY

2 World Health Organization. World health statistics 2016. Geneva: World Health
Organization, 2016. http://who.int/entity/ gho/publications/world_health_statistics/ 2016/en/index.html

3 Richardson E, Malakhova I, Novik I, et al. Belarus: health system review. Health Syst Transit 2013;15:1-118.

4 OMR. Home. Available: https://omr.by/ home-en

5 Belarus fact sheets. Available: https://gco. iarc.fr/today/data/factsheets/populations/ 112-belarus-fact-sheets.pdf

6 Bray F, Ferlay J, Soerjomataram I, et al. Global cancer statistics 2018: GLOBOCAN estimates of incidence and mortality worldwide for 36 cancers in 185 countries. CA Cancer J Clin 2018;68:394-424.
7 Bruni L, Albero G, Serrano B, et al. ICO/ IARC information centre on HPV and cancer (HPV information centre). Human papillomavirus and related diseases in Belarus. Summary report 17 June 2019 2019.

8 Ferlay J, Ervik M, Lam F, et al. Global cancer observatory: cancer today. Lyon, France: International Agency for Research on Cancer, 2018. https://gco.iarc.fr/today

9 Matylevich O, Mavrichev S, Pletnev A, et al. Proceedings from the 1st International Conference 'Current Concepts and Controversies in Gynecologic and Urologic Oncology'. Int J Gynecol Cancer 2018;28:200-5. 